\title{
Comparison of paradigms in problem solving: Matching to sample, responding to similarity, and oddity
}

\author{
DIANA Z. CASELLA and REESA M. VAUGHTER \\ Fordham University, Bronx, New York 10458
}

\begin{abstract}
The relative difficulty of learning matching-to-sample, responding-to-similarity, and oddity problems by college adults was compared. Results demonstrated that subjects took significantly more trials to learn matching as compared to oddity problems regardless of the paradigm (matching-to-sample or responding-to-similarity) employed. The findings indicated that matching and oddity tasks may not be comparable either in regards to the nature of cognitive processes involved or the ease of solution.
\end{abstract}

Although the difficulty of the oddity task for the younger, as opposed to the older child, is well documented (Croll, 1970; Gollin \& Shirk, 1966), until recently, no developmental data were available which assessed the relative difficulty of matching and oddity tasks in children. Vaughter (in press) compared matching and oddity performance in 5-7-, 8-10-, and 11-13-year-olds and found that although children became more proficient with age at solving both problem types, matching was the more difficult of the two tasks for all age groups. There was the possibility that the matching task was more difficult than the oddity task because of the particular paradigm employed by Vaughter, a response-to-similarity paradigm, to test the utilization of the matching concept. The response-to-similarity paradigm allows for two correct responses because the response manipulandum serving both identical stimuli are operative, and a response to either identical stimulus provides the basis for solution. In contrast, the matching-to-sample paradigm, more frequently employed in studies of matching behavior (Fellows, 1968; Harlow, 1951), allows for one of the identical stimuli to serve as a "sample" (the response manipulandum is inoperative) such that response to only one of the identical stimuli serves as a basis for solution. Compared to the response-to-similarity paradigm, the matching-to-sample paradigm is more similar to the oddity task in which response to only one stimulus, the different stimulus, is rewarded. It was hypothesized that if matching-to-sample was compared to oddity learning, the differential learning rates for the two tasks would show comparability, at least, in such sophisticated problem solvers as college adults.

\section{METHOD}

\section{Subjects}

Forty eight male and 48 female subjects were volunteers from

Lila G. Braine sponsors and takes full editorial responsibility for this paper. Diana Casella's current address is: Department of Psychology, Fordham University, Bronx, New York 10458. undergraduate psychology courses in a large urban university in the Northeast. Subjects' mean age was 20 years 0 months (range $=17$ years 6 months to 25 years 2 months). The occupational statuses of the subjects' families were classified as: (a) $25 \%$ professional, (b) $37.5 \%$ managerial, (c) $7.3 \%$ clerical, (d) $9.4 \%$ craftpersons, (e) $10.4 \%$ service workers, (f) $7.3 \%$ laborers, and (g) $3.1 \%$ students or unemployed.

\section{Apparatus}

The essential features of the totally automated psychological assessment console (TAPAC) were a three-stimulus display screen and the location of response buttons directly beneath each stimulus picture. A paper printout recorded response latencies, correct-incorrect responses, cumulative correct, and response key pressed.

The TAPAC, described by Vaughter (Note 1), was programmed so as to uniformly present to each subject the instructions, the stimulus arrays, and the response feedback in visual ("correct"/"incorrect" lamps) and audio (bell/buzzer tones) forms. Response to an inoperative key resulted in no visual or auditory feedback.

\section{Design}

Subject learned either a matching (presented as a matching-to-sample or a response-to-similarity task) or a comparable oddity task. Following solution on the training task, each subject received two transfer tests. A paradigm (matchingto-sample or response-to-similarity) by problem (matching or oddity) by order of transfer tests (intradimensionalextradimensional or extradimensional-intradimensional) randomized block design was employed. Number of trials and errors to criterion and number of errors made on the intradimensional and extradimensional transfer tests were dependent measures.

In the matching-to-sample paradigm, one of the two identical stimuli always appeared in the center position of the three-stimulus array and functioned as the "sample" to be "matched." The sample response manipulandum was never operative; the odd stimulus never appeared in the center position. The stimulus array employed in the matching-to-sample paradigm were also used in the response-to-similarity paradigm; however, in the latter condition, the center key was operative and response to either of the two identical stimuli was rewarded. Thus, in the matching-to-sample paradigm, the "matching" condition allowed for only one correct response while in the response-to-similarity paradigm, the "matching" condition allowed for two possible correct responses per trial. In the oddity problems, only response to the one odd stimulus was rewarded. In the oddity task to be compared with 
matching-to-sample learning, the center response key was never operative (two-position oddity); in the oddity task to be compared with response-to-similarity learning, the center key was always operative (three-position oddity). An equal number of males and females were randomly assigned color and form problems in each condition.

\section{Procedure}

The subjects were informed that the TAPAC was programmed to give instructions concerning the operation of the machine and the nature of the experiment. The recorded instructions explained that three pictures would appear on the screen when the ready button was pressed, that the subject should look at all the pictures before choosing, and that the subject's goal was to learn to choose a correct picture every time. If the subject had no questions following the instruction period, testing was initiated by pressing the ready button.

The training problem sets constituted single-trial matching or oddity since no particular three-stimulus combination of red, green, blue, squares, circles, and triangles occurred on any two consecutive trials. Learning criterion for the training set was 10 consecutive correct responses. Intradimensional transfer (six trials of unique three-stimulus combinations) tested for generalization of the acquired response strategy (matching or oddity) to new stimuli of the same dimensions as those used in the training set. Extradimensional transfer (six trials of unique three-stimulus combinations) tested for generalization of the acquired response strategy to a new and different dimension. The order of presentation of the transfer test sets was counterbalanced across subjects.

\section{RESULTS}

The mean number of trials to criterion was significantly greater for matching (24.59) than for oddity $(11.17)(\mathrm{F}=12.35, \mathrm{df}=1 / 88, \mathrm{p}>.01)$. There was no significant difference between the mean number of trials to criterion for the matching-to-sample condition (16.12) and the response-to-similarity condition (19.63) $(\mathrm{F}=.84, \mathrm{df}=1 / 88, \mathrm{p}<.05)$. The mean number of errors to criterion was also found to be significantly greater for matching (8.46) as compared to oddity (.86) problems $(\mathrm{F}=11.96, \mathrm{df}=1 / 88, \mathrm{p}>.01)$; however, no significant difference was found between the mean number of errors to criterion in the matching-to-sample (4.11) and the response-to-similarity (5.22) conditions $(\mathrm{F}=.25, \mathrm{df}=1 / 88, \mathrm{p}<.05)$. No significant differences were found in the number of errors made on transfer tests either as a function of paradigm employed $(\mathrm{F}=.65, \mathrm{df}=1 / 88, \mathrm{p}<.05)$, kind of problem received $(\mathrm{F}=3.52, \mathrm{df}=1 / 88, \mathrm{p}<.05)$, or order of transfer test presentation $(\mathrm{F}=1.79, \mathrm{df}=1 / 88$, $\mathrm{p}<.05)$.

To examine response patterns, a two-way analysis of variance was performed on the greatest number of correct responses made between any two incorrect responses given by each of the subjects. A significant main effect was demonstrated for problems $(\mathrm{F}=21.44$, $\mathrm{df}=1 / 92, \mathrm{p}>.01$ ) with the mean number of correct responses between any two incorrect responses being greater for matching (1.90) than for oddity (.11) problems; but no significant difference was found between response patterns in the matching-to-sample
(.92) and the response-to-similarity (1.09) conditions $(\mathrm{F}=.03, \mathrm{df}=1 / 92, \mathrm{p}<.05)$.

\section{DISCUSSION}

The findings of the present study replicate and extend the generality of the previous findings by Vaughter (Note 1). Matching, as compared to oddity, was more difficult for the college adult, regardless of the paradigm employed for testing the utilization of the concept. The adult response patterns in the matching and oddity tasks were similar to those found in children: there were significantly more and longer strings of correct responses interspersed with errors in matching as compared to oddity responding. The matching response pattern, characterized by error dispersal, was taken by Vaughter (in press) to indicate the necessity for the child's internal rehearsal of inhibitory response to the odd stimulus to obtain matching solution.

An examination of the posttest interview transcripts indicated that in oddity problem-solving, $100 \%$ of the subjects verbalized both color and form concepts and the oddity strategy, and no subject employed compound cues for solution. In matching problem-solving, $90 \%$ of the subjects verbalized the concepts, $77 \%$ verbalized the strategy, and $67 \%$ attempted to reach solution by compounding available cues, such as choosing "the one that is the same and on the left." The data suggested that, in the matching task, nonreward for the dominant oddity strategy sends the adult subject in search of a correct strategy, testing hypotheses often complex and irrelevant, which eventuate in added trials and errors to criterion. The findings of the present study also suggest that observed species differences (Harlow, 1958; Skinner, 1950; Wodinsky \& Bitterman, 1953) and within-species differences (Croll, 1970; Ginsburg, 1957; Gollin \& Shirk, 1966; Skinner, 1950; Vaughter, in press) in the relative ease of learning matching and oddity problems may be, but are not necessarily, attributable to methodological dissimilarities between studies and that, in the case of human problem solving, matching and oddity may not be comparable in regard to the nature of the cognitive processes involved in solution.

\section{REFERENCE NOTE}

1. Vaughter, R. M. A developmental investigation of oddity concept formation in children. Federal-Health Research Report, Project No. 1-E-051, U. S. Department of Health, Education. and Welfare, Grant No. OEG-5-71-0030 (509), 1972.

\section{REFERENCES}

Croll, W. L. Response strategies in the oddity discrimination of preschool children. Journal of Experimental Child presch ool children. Jour
Psychology, 1970,9, 187-192.

Fellows, B. J. The discrimination process and development. Oxford: Pergamon Press, 1968.

Ginsburg, N. Matching in pigeons. Journal of Comparative and Physiological Psy chology, 1957, 50, 261-263.

Gollin, E. S., \& Shirk, E. J. A developmental study of oddity-problem learning in young children. Child Development, 1966, 37, 213-217.

Harlow, H. F. Primate learning. In C. P. Stone (Ed.) Comparative psychology (3rd ed.). New Y ork: Prentice Hall, 1951.

Harlow, H. F. Evolution of learning. In A. Roe and G. Simpson (Eds.), Behavior and evolution. New Haven: Yale University Press, 1958.

Skinner, B. F. Are theories of learning necessary? Psy chological Review, 1950, 57, 193-216.

Vaughter, R. M. A developmental investigation of oddity and matching. Journal of Genetic Psy chology, in press.

wodinsky, J., \& Bitterman, M. E. The solution of oddity-problems by the rat. American Journal of Psy chology, 1953, 66, 137-140.

(Received for publication March 24, 1975.) 